\title{
Automatic Fiscal Stabilisers in EMU: A Conflict between Efficiency and Stabilisation?
}

\author{
Marco Buti, Carlos Martinez-Mongay, Khalid Sekkat and \\ Paul van den Noord*
}

\begin{abstract}
It is often claimed that tax and welfare reforms that aim at enhancing efficiency may come at the cost of cyclical stabilisation. Reducing the generosity of welfare systems and lowering taxes may boost efficiency and output, and improve market adjustment to shocks. But, by reducing the size of automatic stabilisers, it may also imply less cyclical smoothing. This would be unwelcome in EMU given the loss of national monetary autonomy and the well-known pitfalls of active fiscal management. This paper argues that the alleged trade-off between efficiency/flexibility and stabilisation may not exist. We show that, if the initial level of the tax burden is high, reducing it may lead to higher output stabilisation in the event of a supply shock and higher inflation stabilisation in the event of a demand shock. Simulations show that European countries - especially small ones - might have a tax burden close to or even higher than the threshold level. (JEL E52, E61, F42)
\end{abstract}

\section{Introduction}

The issue of how to adapt to shocks in a situation in which countries do not dispose any longer of national monetary policy has been key in the debate on EMU since the early 1990s. It is usually recognised that fiscal policy has to play a more important role in smoothing shocks, especially if they originate on the demand side. However, in order to avoid the typical pitfalls of fiscal finetuning, the main focus has increasingly been put on the work of automatic stabilisers. This view is codified in the Stability and Growth Pact whose "fiscal philosophy" implies that countries should set a structural target of close to balance or surplus and simply let automatic stabilisers play. The empirical evidence shows that countries with a more generous welfare state and a large and progressive tax system tend to extract a larger smoothing from automatic stabilisation (European Commission, 2001).

* Marco Buti and Carlos Martinez-Mongay are from the European Commission, Khalid Sekkat from the European Commission and the Université Libre de Bruxelles and Paul van den Noord from the OECD.

This article draws on a larger study (Buti et al., 2002). The opinions expressed in this paper are the authors' only and should not be attributed to the institutions they are affiliated with. 
However, while the literature focuses on the demand implications of automatic stabilisers, there are a number of ways in which fiscal stabilisers may impinge on the supply side (Van den Noord, 2000). On the positive side, avoiding recurrent large under-utilisation of resources may have favourable supply-side effects if it prevents under-investment in, and failure to maintain, physical and, more importantly, human capital. Moreover, the literature strongly suggests that, in order to reduce distortions, it is better to keep tax rates stable over the cycle, and hence allow automatic fiscal stabilisers to operate, than to adjust tax rates from one year to another. Similar arguments will apply to adjusting spending parameters such as unemployment benefit rates. ${ }^{1}$

But there are also negative supply-side effects involved in using automatic fiscal stabilisers. Automatic fiscal stabilisation is often created by mechanisms that allow people and businesses affected by changing economic circumstances to delay their adjustment to change. Such mechanisms include the functioning of social security systems, labour market institutions and many parts of tax systems. In a world where automatic stabilisers are allowed to operate as a rule, workers are less concerned with possible adverse externalities of high wage demands. Moreover, they may anticipate that pay rises will not prompt any significant increase in labour supply, on the assumption that unemployed workers are "trapped" to a large extent in the social security system which, as noted, is a main vehicle of automatic stabilisation. To the extent that these negative supply effects prevail, automatic stabilisers may come at a cost in terms of efficiency. Not only would they negatively affect potential output, but also hinder the appropriate response to supply shocks. As a result these tend to be longer lasting.

The flip side of this conclusion is that policy makers' efforts to streamline the welfare state and bringing down the tax burden in the pursuit of better efficiency and more flexible markets would come at a cost in terms of less demand smoothing via the automatic stabilisers. This trade off between stabilisation and efficiency would be particularly unpalatable in EMU countries, since they already have lost national monetary policy and the exchange rate as adjustment mechanisms to country-specific shocks. Indeed, EMU members would ideally aim for both stronger fiscal stabilisation and faster structural adjustment: the first to tackle temporary demand shocks, the second to respond to lasting supply shocks (Buti and Sapir, 2002, and Buti, von Hagen and Martinez-Mongay, 2002).

1 Automatic stabilisation can also be justified on the ground that the government faces fewer liquidity constraints and a lower risk premium than the private sector and therefore is likely to be more efficient at consumption smoothing through cyclical downturns than households are. 
Fortunately this difficult trade-off may not always be relevant. There may be a critical level of the tax burden beyond which a reduction in taxation may not only yield better efficiency, but, depending of the nature of economic shocks, also render fiscal automatic stabilisers more effective. As a result, under certain circumstances, a reduction in the tax burden might carry a "double dividend" of efficiency gains and better fiscal stabilisation properties. This conclusion draws on evidence that lower taxation improves the terms of the short-run inflation-unemployment trade off (i.e. makes the Phillips curve flatter) by reducing the wedge between the marginal cost of labour and the marginal takehome pay. This is encouraging for countries with high tax burdens that are considering a reduction in the size of the public sector.

This article starts out examining the transmission channels of automatic stabilisers, with the focus on the supply channel of automatic stabilisers in addition to the standard demand channel. This is followed by discussion of the determinants of the critical level of the tax burden mentioned above. Before concluding in the final section, we present simulations with the OECD's econometric model INTERLINK that provide empirical support for our findings.

\section{A supply-side channel of automatic stabilisers}

The basic tenet of this paper is that automatic stabilisers operate not only on the demand side through their impact on disposable income, but also on the supply side. Distortionary taxes affect the level of equilibrium unemployment and potential output. ${ }^{2}$ What is important in our analysis, however, is the impact of distorting taxes on the reaction of output to unexpected inflation, that is the slope - not the position - of the aggregate supply curve. This notion is not new as such, as it is rooted in existing theoretical and empirical evidence, but is usually not considered in assessments of the stabilising features of automatic stabilisers. ${ }^{3}$

2 See, e.g. Kneller, Bleaney and Gemmel (1999), Van den Noord and Heady (2001) and OECD (2002). OECD (2000) estimates that an increase in the tax share in GDP by 1 percentage point reduces output per working-age person in the long run by 0.6 to 0.7 percent.

3 For example Hairault et al. (2001) used a dynamic stochastic imperfect competition model to show that introducing some distortive taxation increases both allocation efficiency and stabilisation. The government is assumed to tax firms' input (labour and capital) and to transfer tax revenues to households in a lump sum way. They identified the optimal of tax rate that maximise welfare. The authors also showed that when households are averse to work hours' fluctuations, labour supply is increasing in tax (subsidy) rate. On the empirical side, Auerbach and Feenberg (2000) assessed the extent to which a tax system with rates rising with respect to income serve to stabilise output through labour supply conditions. Their results confirm that such progressive income tax may help to stabilise output via its effect on the supply of labour and suggest that this effect may even be of similar magnitude to the more traditional path of stabilisation through aggregate demand. 
A slope-effect on the aggregate supply curve will occur if workers pass through the cyclical variations in their tax burden at least partly onto employers. This implies that there is "real wage resistance" in an imperfect labour market. ${ }^{4} \mathrm{We}$ argue that the more progressive the tax system is, the stronger will be the impact of (un-)employment on wages. At first sight this contradicts the standard finding in union-wage models that progressive taxation moderates wage claims because it reduces the loss associated with a fall in wage income per worker without affecting the gain in wage income associated with increased employment. However, these models are based exclusively on the behaviour of unions and ignore the impact of progressive taxation on search efforts, consumption-leisure trade-offs and efficiency wages. These mechanisms may be shown to change the sign of the impact of progressive taxes on wage claims from negative to positive (Naess-Schmidt, 2002). ${ }^{5}$

It is now easy to see that, provided that taxes are progressive and there is sufficient wage resistance, the reaction of unemployment to an inflation surprise is smaller the larger the tax burden. The intuition for this result is clear. Take the case of a positive inflation surprise. As employers demand more labour to increase production, they will have to pay higher wages to cover not only for the higher prices but also on account of the fact that wages move up onto a higher tax bracket; this tends to limit the rise in production. ${ }^{6}$

The standard model which neglects the effect of taxes on supply predicts that automatic stabilisers stabilise output and inflation in the event of demand shocks and stabilise output, but destabilise inflation under supply shocks (Blanchard, 2000, Brunila, Buti and in't Veld, 2003, and European Commission, 2001). In this standard model, automatic stabilisers operate only on the demand side. Higher stabilisers imply a lower effect of inflation on demand. In the output-inflation space, the aggregate demand schedule is steeper and displays smaller shifts in the event of shocks. The basic difference in our thinking is that, as stressed earlier, automatic stabilisers operate not only on the demand side, but also on the supply side: higher stabilisers - which means a higher level of taxes - make the supply schedule steeper.

4 Evidence of "real wage resistance" in continental Europe is found by Daveri and Tabellini (2000), but not by Layard (1997) who finds that in the long-run tax neutrality holds. Notice, however, that what is crucial for our analysis is real wage resistance in the short run. Hence the results below are not incompatible with long run neutrality of taxes. For an overview of the debate, see Carone and Salomäki (2001).

5 It is consistent with a situation where unemployment benefits, and hence the reservation wage, is fully indexed on the real wage rate (Pissarides, 1998).

6 For this to hold true it must be assumed that governments fail to provide an offsetting tax break to moderate wage demands, i.e. do not pursue an incomes policy. But this is consistent with the basic assumption of our analysis: governments solely and fully rely on automatic stabilisers, hence do not modify the tax and spending parameters in response to cyclical fluctuations in economic activity. 
We have developed a simple theoretical model to formalise these notions in Buti et al. (2002). Our model is a version of the standard AD-AS model of a monetary union composed of two countries and closed vis-à-vis the rest of the world. It contains a simple IS aggregate demand equation and a Lucas-Phillips supply equation for each country. A crucial assumption is that the slope of the supply function depends on taxes, as argued above. The aggregate demand and supply equations are complemented with the policy rules followed by the fiscal and monetary authorities. The central bank is assumed to aim at stabilising inflation and output of the currency area as a whole, according to a Taylor rule. For the fiscal authority, we assume that, in line with the Stability and Growth Pact, the two governments pursue a neutral discretionary policy, which implies that they set a target for the structural budget balance and let automatic stabilisers play symmetrically over the cycle. ${ }^{7}$ Below we discuss a graphical presentation of our findings.

The left panel of Figure 1 pictures the case of a negative supply shock under a "low" and "high" tax rate $(t)$ according to the standard model - i.e. ignoring the supply channel. The initial equilibrium, E, corresponds to natural level of output $\left(Y^{*}\right)$ and the optimal rate of inflation as targeted by the central bank $\left(\pi^{*}\right)$ in the "home" country (for simplicity we ignore the results for the "foreign" country). The slope of the demand curve is higher (in absolute terms) with a high tax rate than with a low one. The reason is that the higher the tax rate, the stronger will be the cushioning effect of automatic stabilisers on demand after an economy has been hit by rise in inflation. A rise in inflation will lead to a fall in demand on various accounts, most prominently a weakening in international competitiveness, a decline in real disposable income and a tightening of monetary policy.

Note that the latter effect, in an EMU context, is strongest in the largest economies whose weight in the central bank's reaction function is biggest. Automatic stabilisers provide an offset, and hence reduce the impact of inflation on demand and make the demand curve steeper. A supply shock induces a shift of the supply curve to the left. The new equilibrium point is now at A with a low tax burden and at B with a high tax rate. One can easily notice that the new equilibrium level of output is further away from the initial level with a low tax rate than with a high one. The reverse emerges for inflation. Hence, in this case an increase in the tax rate from a low value to a high one is output stabilising but inflation destabilising.

7 This is the definition of a "well behaved" fiscal authority, according to Alesina et al. (2001). For more sophisticated reaction functions of fiscal authorities in EMU, see Buti, Roeger and in't Veld (2001) and Buti and Giudice (2002). 
Figure 1

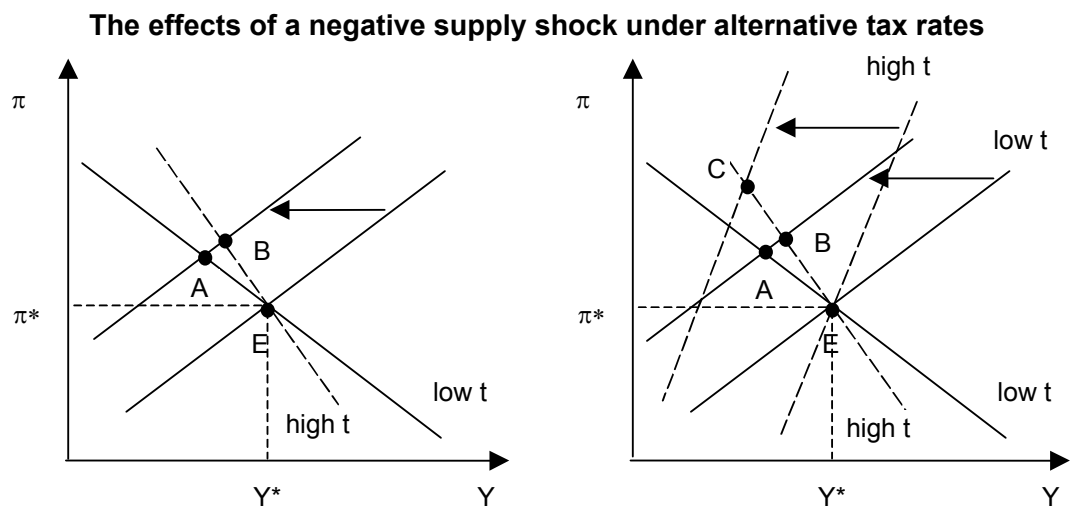

The increase of the tax rate may become, however, output destabilising if the supply curve also becomes steeper due to high taxation, as shown in the second panel. This feature emerges if, for a given rise in the tax burden, the supply curve becomes steeper fast enough relative to the change in slope of the demand curve to produce this result. This, in turn, depends on the size of the tax distortion: the more distorting the tax system, the steeper will be the supply curve for a given tax burden. The new equilibrium point is now at $\mathrm{C}$ with a high tax burden. It is clear from the graph that the new equilibrium level of output is further away from the initial level with a high tax rate than with a low one. Inflation is always further away from its optimal level with a higher tax rate. Hence, in this case an increase in the tax rate from a low value to a high one is both output destabilising and inflation destabilising.

The changes of taxation to become output-destabilising rise with the supply curve becoming steeper. ${ }^{8}$ On the other hand, the output destabilising-effect diminishes as the demand curve become steeper. Since the slope of both curves depends on the tax rate, the threshold level for the tax rate beyond which further increase of taxation is destabilising for output in the event of a supply shock depends on the relative sensitivity of demand and supply to taxation. This, in turn, depends on the openness of the economy: the more open the economy, the lower will be the fiscal demand multiplier and therefore the steeper will be the supply curve relative to the demand curve for a given tax burden. Therefore, small open economies are more likely to face adverse fiscal stabilisation properties in the face of a supply shock than larger, relatively closed economies for a given level of taxation.

8 In the extreme case where the supply curve becomes vertical the shock would not be smoothed at all and output would fall by the same extent of the shock. 
Figure 2

The effects of a positive demand shock under alternative tax rates
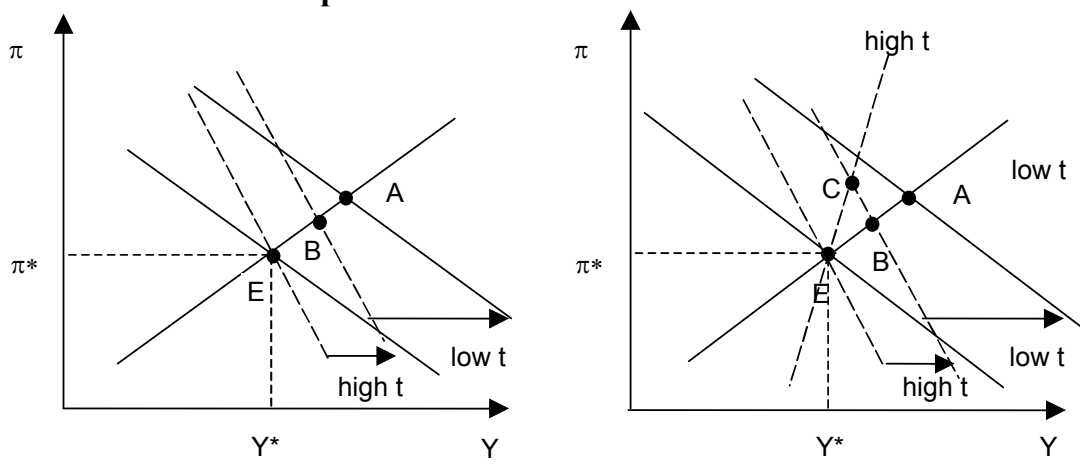

The case of a positive demand shock is illustrated in Figure 2. Again, the figure pictures the cases under "low" and "high" tax rate. The slopes of both demand and of supply are higher (in absolute terms) with a high tax rate than with a low one. In both cases, the equilibrium, E, corresponds to optimal levels of output $\left(Y^{*}\right)$ and inflation $\left(\pi^{*}\right)$. A positive demand shock induces a shift of the demand curve to the right. ${ }^{9}$ The new equilibrium points when only the steeper demand curve is considered (left panel) are now at A with a low tax rate and at $\mathrm{B}$ with a high one. The new equilibrium level of output is closer to the optimal level with a high tax rate than with a low one. A similar picture emerges for inflation. Hence, in this case an increase in the tax rate is both output and inflation stabilising.

Taking into consideration the possibility of the supply curve becoming steeper as well, automatic stabilisation may become, however, inflation destabilising. From the second panel in Figure 2, one can notice that this will still lead to a closer output to its optimal level but to a higher inflation. Hence, in this case an increase in the tax rate risks becoming inflation destabilising beyond a certain point if the slope of the supply curve is more sensitive to the tax burden than the slope of the demand curve.

9 Note that while the vertical shift is always the same, the horizontal shift is smaller for higher tax rates as the impact of the demand shock is muted by the automatic stabilisers. 


\section{A "critical" tax rate}

Above we have shown that, through their impact on the supply side, higher automatic stabilisers can lead to a lower output stabilisation under supply shocks, and inflation destabilisation under demand shocks. In terms of policy behaviour, if we assume that fiscal authorities care mainly about output and the central bank about inflation, the risk of a policy conflict becomes more acute in the event of supply shocks and, contrary to the common wisdom, may occur also in the event of demand shocks. The results attained so far are summarised in Table 1.

Table 1

Effect of a rise in taxes on output and inflation stabilisation

\begin{tabular}{|c|c|c|c|c|}
\hline & \multicolumn{2}{|c|}{ output } & \multicolumn{2}{|c|}{ inflation } \\
\hline $\begin{array}{l}\text { Initial level of taxes } \\
\text { shocks }\end{array}$ & Low & High & Low & High \\
\hline demand shock & - & - & - & + \\
\hline supply shock & - & + & + & + \\
\hline
\end{tabular}

From the above discussion, it emerges that the initial level of taxation is important in assessing the implications for stabilisation of tax and benefit reforms. For at "low" level of taxes, the traditional stabilisers are likely to dominate. However, under a "high" tax burden, a further increase in it may imply perverse stabilisation effects. ${ }^{10}$ This suggests the existence of a "critical" tax rate above which some of the stabilising properties of automatic stabilisers become perverse. A key question is what factors determine this critical tax rate.

10 Similar effects are found also by Galí (1994), in a real business cycle model. Wijkander and Roeger (2002) have also challenged the conventional wisdom that progressivity enhances stability. When comparing the stabilising potential of various components of the budget in France and Germany, these authors conclude that progressive direct taxes on income and wealth, might be less efficient stabilisers than less-distortionary taxation, such as proportional taxes on production. 
We have derived an explicit expression for the critical tax rate in Buti et al. (2002). The mathematics involved very quickly become complex, but it is nevertheless possible to draw some intuitively appealing conclusions:

- First, it appears that lower tax progression reduces the negative supply effects of taxation, thereby allowing a higher tax rate for a given size of automatic stabilisers. In other words, there exists a trade-off between the progressiveness of taxation and its level: the less progressive taxes are, the higher will be the critical tax rate above which automatic stabilisers become perverse.

- Second, the threshold level of the tax rate above which automatic stabilisers become destabilising may be shown to depend on the responsiveness of demand to fiscal or monetary policy impulses stemming, respectively, from the automatic stabilisers and the central bank's reaction function. The stronger this responsiveness, the higher tax rate can be "afforded" without risking perverse stabilisation properties.

- Third, the threshold level depends on the weight of inflation (as opposed to output) in the central bank's reaction function. The critical tax rate will be higher if the central bank is more price-stability prone than if it is more concerned by output stability because a hawkish central bank will choke off the inflationary effect of automatic stabilisers. Interestingly, this implies that the incentives to reform the tax system are lower under a conservative central banker, although incentives to reform the tax system on efficiency grounds would remain equally strong.

\section{Figure 3}

The critical tax burden for different sizes of the "home country's" economy in a two-country model

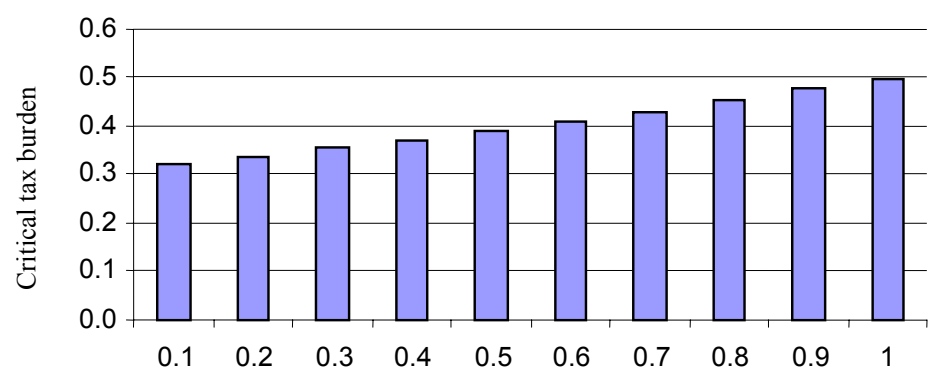

Realtive share of the home country in total output of the currency area 
- Fourth, a greater openness of the economy reduces the threshold level of taxation. The reason is that the demand effects of automatic stabilisers leak out via foreign trade, implying that the negative supply effects predominate more quickly, i.e. even at a lower level of taxation. This is analytically similar to the second point above, but it is separate because, even if policy transmission is strong, trade leakage will partly divert its impact to other countries.

- Fifth, the size of the economy matters to the extent this determines (in an EMU context) the country's weight in the central bank's reaction function. The larger the economy, the bigger its weight, hence the higher will be the threshold tax rate. Since openness and size of the economy are typically correlated, these factors tend to be mutually reinforcing. Smaller economies in the EMU are thus facing stronger incentives to reform their tax systems than the bigger ones.

In Buti et al. (2002) we provide also a tentative quantification of the critical tax rate by parametrising the theoretical model attributing reasonable values to the coefficients, broadly in line with the estimated parameters of OECD's INTERLINK model.

This confirms that the key determinant of the critical tax rate is the size of the economy. This implies that the larger the economy, the larger will be the demand impact of automatic stabilisers relative to the supply impact. Hence a large country could "afford" higher tax burden without jeopardising the stabilisation properties of automatic stabilisers - i.e. the higher the critical tax rate would be. The computed values of the threshold are presented in Figure 3. This result thus confirms that, in small open economies, adverse stabilisation effects may occur at a size of government that is considerably smaller. Importantly, these calculations suggest that the critical tax rate must be below half of GDP in small open economies. We have also experimented with other parameters, but the resulting critical tax rates appeared to be relatively insensitive. Within plausible intervals for the numerical parameters, the relative size of the economy seems to be the main determinant of the critical tax rate.

\section{Empirical evidence: simulations with INTERLINK}

In order to back our theoretical result and check the plausibility of the numerical calculations above, we have simulated standard supply and demand shocks with a mainstream empirical economic model, the OECD's INTERLINK model. This model, which has separate modules for each of the OECD member economies as well as a detailed international trade block, captures the basic macroeconomic relationships that operate (Dalsgaard et al., 2001). 
We compare the results for a typical small open and a typical large economy in the euro area, on the assumption that, for a given tax burden, the sign switch is more likely to occur for the small economy than for the large one. For this purpose we chose Belgium and France, which have similar fiscal sizes (close to 50 percent to GDP) but a very different degree of openness. We have modified the supply block of Belgium to bring its structure in line with that of the G7 economies in order to enhance the cross-country comparability (see also Hoeller et al., 2002). The favourable demand shock is a once-and-for all increase in private consumption and exports equivalent to $1 / 2$ percent of baseline GDP each and the adverse supply shock is a once-and-for all 1 percent decrease in labour efficiency. In all simulations monetary policy is assumed to respond according to a Taylor rule whereby interest rates are raised above their equilibrium level if either inflation rises above a target of $1 \frac{1}{2}$ percent or the output gap turns positive. The weights attached to inflation and the gap are fixed at 1.2 and 0.2 , respectively, and the equilibrium interest rate is set at 4 percent. These parameter values are in line with recent studies of the ECB's monetary policy reaction function (von Hagen and Brückner, 2001). In the case of an asymmetric shock, the weights are multiplied by the Belgian and French shares in euro-area GDP of around 4 and 20 percent, respectively.

In a first set of simulations fiscal stabilisers have been 'switched off' by ensuring that the primary fiscal balance (as a percent of GDP) always stays at its baseline level (labelled simulation A). In practical terms this means that the standard supply or demand shock is complemented by a discretionary fiscal policy shock that exactly offsets the endogenous changes in the primary balance stemming from the standard shock. This simulation thus gauges the economy's response to a standard demand or supply shock in the absence of automatic fiscal stabilisers. The results are shown in Table 2.

- As expected, under an asymmetric demand shock, real output initially increases relative to baseline, but over time converges towards baseline. This reflects the tendency of actual output to return to potential, which in itself is largely unaffected by the demand shock. The boost to inflation is, in contrast, relatively persistent. Even though the automatic stabilisers are switched off, the fiscal balance (not shown in the table) improves a bit, owing to the initial increase in output and the associated reduction in debtinterest expenditure relative to output. Interest rates increase somewhat initially, but not by enough to result in adverse public debt dynamics.

- After an asymmetric supply shock, again as expected, output falls relative to baseline in the short-to-medium run, but this decline is more persistent as potential output falls in concert (the output gap, however, converges to zero). The inflation rate initially sharply increases in response to the hike in unit labour cost, but this effect is gradually eroded as the price level 
stabilises relative to baseline. It is noteworthy that the inflation effect is much stronger in the large economy, which is expected as the lower import share in demand boosts the cost-price multipliers. This result emerges even though the large economy has a higher weight in the decisions of the central bank, which by itself exert a relatively more stabilising effect on inflation.

Table 2

The smoothing impact of automatic stabilisers and the nature of shocks

Changes from baseline

\begin{tabular}{|c|c|c|c|c|c|c|c|c|c|c|c|c|}
\hline \multirow[b]{3}{*}{ Year } & \multicolumn{6}{|c|}{ Demand shock 1} & \multicolumn{6}{|c|}{ Supply shock 2} \\
\hline & \multicolumn{3}{|c|}{ GDP level (\%) } & \multicolumn{3}{|c|}{$\begin{array}{c}\text { Inflation rate } \\
\text { (\% points) }\end{array}$} & \multicolumn{3}{|c|}{ GDP level (\%) } & \multicolumn{3}{|c|}{$\begin{array}{c}\text { Inflation rate } \\
\text { (\% points) }\end{array}$} \\
\hline & 1st & 2nd & 5th & 1st & 2nd & 5th & 1st & 2nd & 5th & 1st & 2nd & 5 th \\
\hline \multicolumn{13}{|l|}{ Typical small economy ${ }^{3}$} \\
\hline \multicolumn{13}{|l|}{ Automatic stabilisers switched: } \\
\hline A. Off & 0.6 & 0.7 & -0.1 & 0.1 & 0.5 & 1.3 & -0.1 & -0.1 & -0.2 & 0.7 & -0.1 & 0.0 \\
\hline B. On & 0.6 & 0.6 & 0.0 & 0.1 & 0.5 & 1.4 & -0.1 & -0.1 & -0.2 & 0.7 & -0.1 & 0.2 \\
\hline C. On, no supply effect & 0.6 & 0.6 & 0.1 & 0.1 & 0.4 & 1.3 & -0.1 & -0.1 & -0.1 & 0.7 & -0.1 & 0.1 \\
\hline Total impact (B-A) & -0.1 & -0.1 & 0.2 & 0.0 & 0.0 & 0.1 & 0.0 & 0.0 & -0.0 & 0.0 & 0.1 & 0.1 \\
\hline Demand impact (C-A) & -0.1 & -0.1 & 0.3 & 0.0 & -0.1 & 0.0 & 0.0 & 0.0 & 0.0 & 0.0 & 0.0 & 0.1 \\
\hline Supply impact (B-C) & 0.0 & 0.0 & -0.1 & 0.0 & 0.1 & 0.1 & 0.0 & 0.0 & -0.1 & 0.0 & 0.1 & 0.1 \\
\hline \multicolumn{13}{|l|}{ Typical large economy 4} \\
\hline \multicolumn{13}{|l|}{ Automatic stabilisers switched: } \\
\hline A. Off & 0.9 & 0.9 & 0.4 & 0.1 & 0.6 & 0.9 & -0.3 & -0.4 & -0.9 & 1.4 & 0.7 & 0.4 \\
\hline B. On & 0.7 & 0.7 & 0.4 & 0.1 & 0.5 & 0.8 & -0.2 & -0.3 & -0.8 & 1.4 & 0.8 & 0.5 \\
\hline C. On, no supply effect & 0.7 & 0.7 & 0.4 & 0.1 & 0.5 & 0.7 & -0.2 & -0.3 & -0.7 & 1.4 & 0.7 & 0.5 \\
\hline Total impact (B-A) & -0.2 & -0.2 & -0.0 & 0.0 & -0.1 & -0.1 & 0.0 & 0.0 & 0.2 & 0.0 & 0.1 & 0.2 \\
\hline Demand impact (C-A) & -0.2 & -0.2 & 0.0 & 0.0 & -0.1 & -0.2 & 0.0 & 0.0 & 0.2 & 0.0 & 0.0 & 0.2 \\
\hline Supply impact (B-C) & 0.0 & 0.0 & 0.0 & 0.0 & 0.0 & 0.1 & 0.0 & 0.0 & 0.0 & 0.0 & 0.0 & 0.0 \\
\hline
\end{tabular}

1. $A \frac{1}{2}$ percent of GDP sustained increase in private consumption and exports.

2. A 1 percent sustained reduction in labour efficiency.

3. Belgium

.

Source: $\mathrm{OECD}$ Secretariat.

In a second set of simulations (labelled B in Table 2), discretionary fiscal policy responses are removed, allowing the primary budget balance to move freely in response to the variations in economic activity relative to baseline. Comparing these simulations with the previous ones gives an impression as to the extent by which the economic impact of demand or supply shocks is changed by the working of automatic fiscal stabilisers. We find the following:

- Not surprisingly, the impact of the demand shock on output is muted by the automatic stabilisers, with, however, the mitigating impact twice as strong in the larger country as compared to the smallest country. The same holds for the impact of the demand shock on inflation. So, these simula- 
tions broadly confirm the presumption that automatic stabilisers matter less in a small open economy.

- In response to the adverse supply shock, output is again falling, but the automatic stabilisers now ensure this fall to be somewhat smaller in the large economy, but not in the small economy where the impact of the automatic stabilisers on output is perverse as predicted by the theoretical model. In both countries inflation increases by a bit more than compared with a situation where automatic stabilisers are not allowed to operate, confirming that the inflation impact of the automatic stabilisers is perverse in response to a supply shock in both cases.

The upshot of these simulation results is that the tax burden must be close to or just beyond its "critical level" in the smallest economy, whereas in the larger economy it is found to be below this critical level. Put differently, and generalising the results, in a typical small economy the critical tax burden would be roughly half of GDP or less, while in a typical large economy it would be more than half of GDP.

In a third set of simulations, we again allow the automatic stabilisers to work freely, but in addition assume the unemployment responsiveness of wages to be lower (simulation $\mathrm{C}$ in Table 2). In particular, we assume that the semielasticity of wage growth with respect to the level of unemployment falls by allowing for the impact of tax progression on wage responsiveness in both countries. We find:

- The impact of an asymmetric demand shock on output is somewhat muted by the supply-effect of the automatic stabilisers, but the impact is very small and the demand channel clearly dominates. Meanwhile the supply channel reduces the stabilising impact on prices, and in the case of the smaller country is responsible for changing it into a destabilising impact.

- Concerning the adverse supply shock, the supply channel is entirely responsible for boosting the adverse output impact in the small country. By contrast, the supply impact on output is virtually zero in the larger country, explaining why the stabilisation properties of automatic stabilisers on output are preserved. The supply channel is also responsible for the perverse inflation impact in the case of a demand shock affecting the small country.

In conclusion, the sign switches that compromise the stabilising impact of automatic stabilisers on inflation and output in a small open economy in response to, respectively, a demand or a supply shock, are entirely due to the operation of the supply channel. Importantly, the experiment suggests that the threshold tax burden above which sign switches occur in a typical small open economy in EMU could be below half of GDP and therefore potentially relevant. 


\section{Conclusions}

This paper challenges the conventional view that high and progressive tax systems are efficiency-decreasing but enhance output stabilisation in the event of shocks.

Ceteris paribus, progressive tax systems lead to a lower budget deficit (contraction of fiscal policy) in good times, while the deficit would increase in recessions (fiscal expansion). Moreover, large and progressive tax systems usually go hand in hand with more generous systems of social protection. Although social benefit programmes mainly have an equity role, as well as potential efficiency effects when they correct market failures, some of them also act as automatic stabilisers. Unemployment benefits make up the clearest example. Since distorting taxes have a pervasive impact on potential growth, a trade-off between stabilisation and efficiency seems to arise within the standard AD-AS framework. If there is a positive relationship between the size of automatic stabilisers and distortive taxation, any reform aiming at lowering distortions and enhancing efficiency will come at the expense of macroeconomic stability.

This issue is at the heart of macroeconomic policy design in EMU. If, as suggested by the standard model, there were a trade off between stability and flexibility, EMU members - having given up national monetary independence - would not dispose of enough policy instruments to deal with idiosyncratic shocks.

However, this paper suggests that under certain circumstances such a trade-off might not exist. As marginal tax rates increase in progressive regimes so do average rates. Within our model, rising tax rates enhance market distortions and reduce the output stabilisation in the event of supply shocks and inflation stabilisation in the event of demand shocks. The simulations presented above tend to support this view.

If our conclusions are right, unless there is a clear predominance of demand over supply shocks, one should not worry about the possible adverse effects on stabilisation of the tax reforms that across the EU are lowering marginal and average tax rates across the whole income scale (European Commission, 2000a; 2000b; 2001).

It goes without saying that the analysis in this paper is far from saying the last word on the relations between efficiency and flexibility, on the one hand, and cyclical stabilisation, on the other hand. Obvious improvements concern the theoretical model (which is overly simple and static in nature) and the description the behaviour of policy makers. Moreover, the empirical evi- 
dence is still tentative and should be supplemented by more thorough econometric investigation.

An issue that arises naturally is the apparent contradiction between our conclusion that adverse stabilisation effects may arise at lower levels of taxation in smaller economies and the finding that small, open economies tend to have larger governments (see the seminal contribution by Rodrik, 1998, and, recently, Martinez-Mongay, 2002). Two explanations can be offered. First, whatever their initial level, higher taxes are output-stabilising in the event of demand shocks. Hence, if output stabilisation is the main goal of fiscal authorities and demand shocks (are expected to) prevail, larger governments would ensue. However, EMU may bring a change in the composition of shocks by increasing the relative frequency of supply compared to demand shocks. ${ }^{11}$ If so, large automatic stabilisers may no longer be optimal. Second, to the extent the tax burden remains below the critical tax burden, a rise in it is stabilising, although increasingly less so. This, coupled with a higher exposure to shocks, may imply larger governments in small open economies. Econometric analyses based on past data may capture this effect. However, in recent years, the actual tax burden may have reached or even exceeded the critical one.

Our analysis indicates that tax reforms aiming at lowering marginal effective tax rates and the tax burden may enhance the stabilisation properties of automatic stabilisers, especially in small euro area economies. Hence they face a lesser dilemma between structural reform and stabilisation policy. This may contribute to explain their greater reform efforts and better performance compared with the big "laggards". However, to the extent that EMU brings about greater trade integration, the incentives to step up reform efforts would increase also in the large euro area countries.

\section{References}

Alesina, A., O, Blanchard, J. Galí., F. Giavazzi. and H. Uhlig (2001), Defining a Macroeconomic Framework for the Euro Area, CEPR, MECB, 3.

Auerbach, A.J. and D. Feenberg (2000), "The Significance of Federal Taxes as Automatic Stabilizers", Journal of Economic Perspectives 14(3), 3-56.

11 Buti, Pench and Sestito (1999) argue that EMU's macroeconomic framework could lead to less policy-induced demand shocks while the increase in market competition brought about by the euro could entail more supply-related shocks. 
Blanchard, O. (2000),“Commentary”, Federal Reserve Bank of New York -Economic Policy Review 16(1), 69-74.

Brunila, A., M. Buti and J. in’t Veld (2003),"Fiscal Policy in Europe: How Effective Are Automatic Stabilisers?", Empirica, forthcoming.

Buti, M. and G. Giudice (2002), "EMU's Fiscal Rules: What Can and Cannot Be Exported", Journal of Common Market Studies 40(5), 823-847.

Buti, M. and A. Sapir (2002), "EMU in the Early Years: Differences and Credibility", in: M. Buti and A. Sapir (eds.), EMU and Economic Policy in Europe - The Challenge of the Early Years, Cheltenham: Edward Elgar.

Buti, M., J. von Hagen. and C. Martinez-Mongay, (eds. 2002), The Behaviour of Fiscal Authorities - Stabilisation, Growth and Institutions, Basingstoke: Palgrave.

Buti, M., L. R. Pench and P. Sestito (1999), "European Unemployment: Contending Theories and Institutional Complexities. A Summary of the Policy Arguments", in: C. Lucifora and W. Salverda (eds.), Policies for Low Wage Employment and Social Exclusion, LoWER, F. Angeli.

Buti, M., W. Roeger. and J. in't Veld (2001), "Stabilising Output and Inflation: Policy Conflicts and Coordination under a Stability Pact", Journal of Common Market Studies 39, 801-828.

Buti, M., C. Martinez-Mongay , K. Sekkat and P. van den Noord (2002), "Automatic Stabilisers and Market Flexibility in EMU: is There a Tradeoff?", OECD Economics Department Working Paper 335.

Carone, G. and A. Salomäki (2001), "Reforms in Tax-Benefit Systems in order to Increase Employment Incentives in the EU", European Commission Economic Papers No. 160.

Dalsgaard, T., C. André and P. Richardson (2001), "Standard Shocks in the OECD INTERLINK Model", OECD Economics Department Working Paper 306 .

Daveri, F. and G. Tabellini (2000), "Unemployment, Growth and Taxation in Industrial Countries", Economic Policy 30, 47-104.

European Commission (2000a), Public Finances in EMU - 2000, European Economy Reports and Studies 3. 
European Commission (2000b), The Contribution of Public Finances to Growth and Employment: Improving Quality and Sustainability, European Commission communication, $\operatorname{COM}(2000)$ 846, Brussels.

European Commission (2001), Public Finances in EMU - 2001, European Economy Reports and Studies 3.

Hairault, J. O., F. Langot and F. Portier (2001), "Efficiency and Stabilization: Reducing Harberger Triangles and Okun Gaps", Economics Letters 70, 209-214

Hoeller, P., C. Giorno and C. de la Maisonneuve (2002), "Overheating in Small Euro Area Economies: Should Fiscal Policy React?", OECD Economics Department Working Papers No. 323.

Galí, J. (1994), “Government Size and Macroeconomic Stability”, European Economic Review 38, 117-132.

Kneller, R., M. F. Bleaney and N. Gemmell (1999), "Fiscal Policy and Growth: Evidence from OECD Countries", Journal of Public Economics 74, 171-190.

Layard, R. (1997), "Preventing Long-term Unemployment", in: D. J. Snower and G. de la Dehesa (eds.), Unemployment Policy. Government Options for the Labour Market, Cambridge: Cambridge University Press.

Martinez-Mongay, C. (2002), "Fiscal Policy and the Size of Governments", in: M. Buti, J. von Hagen and C. Martinez-Mongay (eds.), The Behaviour of Fiscal Authorities - Stabilisation, Growth and Institutions, Basingstoke: Palgrave.

Naess-Schmidt, H. S. (2002), "Progression in Taxation of Earned Income, Wage Formation and Labour Market Performance", Danish Ministry of Finance, Working paper, Copenhagen.

OECD (2000), "Links between Policy and Growth: Cross-country Evidence", Chapter IV, Economic Outlook 68, Paris.

OECD (2002), Tax and the Economy: A Comparative Assessment of OECD Countries, OECD Tax Policy Studies 6.

Pissarides, C. A. (1998), “The Impact of Employment Tax cuts on Unemployment and Wages; The Role of Unemployment Benefits and Tax Structure", European Economic Review 42(1), 155-183. 
Rodrik, D. (1998), "Why Do More Open Economies Have Bigger Governments", Journal of Political Economy 106, 997-1032.

van den Noord, P. (2000), "The Size and Role of Automatic Stabilisers in the 1990s and Beyond", OECD Economics Department Working Papers No. 230

van den Noord, P. and C. Heady (2001), "Surveillance of Tax Policies: A Synthesis of Findings in Economic Surveys", OECD Economics Department Working Papers 303.

von Hagen, J. and M. Brückner (2001), "Monetary Policy in Unknown Territory: the European Central Bank in the Early Years", ZEI Working Paper B 18.

Wijkander, H., and W. Roeger (2002), "Fiscal Policy in EMU: the Stabilisation Aspect", in: M. Buti, J. von Hagen and C. Martinez-Mongay (eds.), The Behaviour of Fiscal Authorities - Stabilisation, Growth and Institutions, Basingstoke: Palgrave. 